Management Learning

\title{
Employers' views of learning and training for an ageing workforce
}

\begin{tabular}{|c|l|}
\hline Journal: & Management Learning \\
\hline Manuscript ID: & MLQ-11-0117.R2 \\
\hline Manuscript Type: & Original Article \\
\hline Keywords: & employers, Learning, Training, older workers \\
\hline Abstract: & $\begin{array}{l}\text { This paper questions how employers view and evaluate the role of learning } \\
\text { and training for older workers in light of the increasing number of older } \\
\text { workers in the labour market. Learning and training opportunities could be } \\
\text { utilised to respond to the 'extending working lives' agenda but interviews } \\
\text { with employers suggest that this is not being done. A small number of } \\
\text { human resource professionals, managing directors and owners were } \\
\text { interviewed to determine what learning opportunities they offered to their } \\
\text { older workers and how these workers' experience could be utilised better. } \\
\text { Respondents implicitly accepted that there were few learning opportunities } \\
\text { for older workers and suggested that they expected this group of workers } \\
\text { to take on additional roles in making learning and experience available to } \\
\text { younger colleagues. Dichotomies in employers' views emerged in that they } \\
\text { differentiated between groups of workers and their need for skills, } \\
\text { experience and the 'right' attitudes. }\end{array}$ \\
\hline
\end{tabular}

\section{SCHOLARONE"}

Manuscripts 


\title{
Employers' views of learning and training for an ageing workforce
}

\begin{abstract}
This paper questions how employers view and evaluate the role of learning and training for older workers in light of the increasing number of older workers in the labour market. Learning and training opportunities could be utilised to respond to the 'extending working lives' agenda but interviews with employers suggest that this is not being done. A small number of human resource professionals, managing directors and owners were interviewed to determine what learning opportunities they offered to their older workers and how these workers' experience could be utilised better. Respondents implicitly accepted that there were few learning opportunities for older workers and suggested that they expected this group of workers to take on additional roles in making learning and experience available to younger colleagues. Dichotomies in employers' views emerged in that they differentiated between groups of workers and their need for skills, experience and the 'right' attitudes.
\end{abstract}

Key words: employers; learning and training opportunities; older workers

\section{Introduction}

The average age of the British workforce has been rising since the late 1980s. Between 1996 and 2008 the proportion of women and men aged between 50 and state pension age (SPA) in employment rose from 61 to 70 and 70 to 73 per cent respectively (ONS, 2009). The Coalition government, in line with changes introduced by the previous government, have abolished the SPA, meaning that there will no longer be a set age at which individuals have to retire. What is not yet clear is whether there will be any changes in employment policies or regulations to ensure that a labour market without the SPA can benefit both employers and employees. The Age and Employment Network (TAEN, 2011a) consider the changes to SPA a short-term fix if they are not accompanied by the creation of suitable jobs and enhancement of work capabilities. This raises questions about the readiness of our society for the 
fundamental demographic changes, which, as this paper will show, are tied up with questions about the appropriateness of workplace learning practices.

Labour market predictions across Europe suggest that the role of older workers will become more important as the size of younger cohorts decreases and as employment rates amongst older workers increase (EC, 2009). In the UK, policies aim to further increase the integration of older workers (50+) (Dini, 2009). The justifications for such policies include tackling poverty and promoting well-being and independence. In addition, it cannot be denied that due to the increased dependency ratio there is an economic and fiscal need to retain workers in the labour market. Yet as Vickerstaff et al. (2008) have shown, there is a 'limited appetite for extending working lives' amongst employees. There are considerable differences between those who may consider retirement a well-earned entitlement; individuals who retire for health reasons; those who are compelled to continue working for financial reasons; and older workers who have an inherently positive relationship with employment and would like to continue working (Ozawa and Lum, 2005). Further differentiation occurs by gender, class, ethnicity, disability, general level of health, caring responsibilities, human capital and the potentially discriminating behaviour of employers and/or colleagues (Porcellato et al., 2010). Although employment rates for older workers have been increasing there are many good reasons why society has not whole-heartedly embraced the 'extending working lives' agenda, with Vickerstaff (2010) questioning the 'unavoidable obligation' of working longer.

Similar issues are noticeable in employers' behaviour. Employers generally benefit from older workers, in particular their soft skills, experience, punctuality and work values (McNair et al., 2007). However, the positive view that employers reportedly have of older workers has not changed their recruitment and retention behaviour (Heywood et al., 2010). Beck (2010) shows that employers favour traditional recruitment practices targeted at young people, e.g. via apprenticeships, though some employers had found that this pool was no longer sufficient to fulfil their needs. Discrimination on the basis of age thus continues to exist (compare Parry and Tyson, 2009, Urwin, 2006). Bowen-Wilson (2011) outlines how difficult employers find it to manage and support older employees, let alone provide them with opportunities for career 
progression. Porcellato et al. (2010) found similarly that employers do not necessarily value the human and intellectual capital that older workers bring to their workplace. The behaviour and preparedness (LCCI and Penningtons, 2011, Hedge, 2008) of employers rather than their rhetoric vis-à-vis older workers is thus, at best, mixed.

Within the discussion of demand and supply for the older labour market (McNair, 2011a and b), issues of training and learning play a comparatively small role (Parry and Tyson, 2011, Porcellato et al., 2010). It is therefore worthwhile briefly rehearsing how important the relationship is. The potential benefits of involving older workers in learning range from improving commitment and involvement of older workers in the labour market (Herrbach et al., 2009) to a much broader delay of some of the physical and mental problems associated with growing old (Phillipson, 2010). The extensive literature (see inter alia Argote, 2011; Geiger and Schreyögg, 2009) on organisational learning and knowledge management, much of it published in this journal, indicates that continuous learning for all people in employment is crucial. Technological developments, increased global competition and the tightness of labour markets that results from economic upheaval further highlight the importance of continuous learning and skill development activities (Maurer, 2001). This literature implicitly assumes that there will be a demand for older workers and their skills as long as they continue to learn. Billett $(1999,2002)$ argues that learning is part of working and that learning is framed by individuals' work activities and the norms and values of the workplace. The required competencies change with work practices and work places, making employability, even for experienced workers, a moving target (Eraut, 2004). There is a resulting need for continuous learning for workers of all ages. This article discusses the particular need for learning for older workers as viewed by employers. Although some employers recognise this need, few are addressing it. This highlights the extent to which organisations will need to reconsider their approach to older workers, learning and training in light of policy changes and the ageing of the workforce.

\section{Methods and the research process}


Different theories and theoretical approaches bear on our understanding of learning. Although Sawchuk's (2008) call for multi-theoretical and multi-methodological thinking cannot be followed here, the foundations for this paper are broad. The backdrop is formed by considerable changes in the demographic make-up of societies and their workforces. In the UK, the speeding up of the timetable to abolish the default retirement age has caught most employers and employees by surprise and left them poorly prepared (LCCI and Penningtons, 2011). It is therefore important to question whether the implications of the changes have been considered in enough depth, in particular when it comes to learning. The foundations for this research are thus located in a range of different literatures including that on the ageing of the workforce, workplace learning, and older workers' learning and training. This approach lends itself to comparing different sectors as it provides a more aggregate perspective. Such comparisons have the drawback that less attention is paid to specific (organisational) contexts and that the focus is less flexible throughout the research process (Bryman, 2004) but have the advantage that broad tendencies within the sectors become visible.

The exploration of these questions are based on research into employers' awareness of their ageing labour force and the potential of utilising various forms of learning as a means to motivate, integrate and, ultimately, retain older workers. Two distinct phases of research were undertaken. The first phase, between July and September 2008, consisted of a research project funded by the East Midlands Learning and Skills Council (LSC). The qualitative research aimed to explore the extent to which employers utilise learning and training activities to bind older workers into employment to extend their working lives. The research focussed on five sectors: construction (mainly in housing); engineering (e.g. car and clock manufacturing); health (public, private and charitable services); logistics; and retail (mixed goods stores and specialist retailers). These sectors contain a range of different types of organisations, activities, occupations and types or levels of workers which are at times conflated under the broad sectoral headings. Where possible, a clearer indication of what type of occupation or worker specific findings related to is provided. Large (100 employees + ), SME and small (less than 50 employees) companies were included with the smallest firm 
employing 3 workers. All employed older workers. Interviews were undertaken with 19 'employers'. Depending on the size of the company, they were either a member of the HR team, the managing director or the owner. The interviews covered background questions such as the area of activity of the organisation and the characteristics of their workforce before exploring policies and practices on older workers, training and learning. To provide a broader context for the research, a further 13 interviews were conducted with the Sector Skills Council for each sector and a range of other key informants on the sector (e.g. trade union) or the older workforce (age and employment organisations). Companies and interviewees were selected on the basis of their willingness to participate in the research. $A$ number had previously worked with the LSC, some were recommended by a Chamber of Commerce but others were contacted 'cold' and randomly from business listings. At least some of the respondents had been active in learning and skill development via their previous engagement with the LSC and Chamber of Commerce and the sample must therefore be considered skewed towards a positive outlook on older workers.

Two years later in November and December 2010, as part of an un-funded follow up to this project, all 19 'employers' that had previously been interviewed were contacted again. Only 7 responded and were available to be re-interviewed for the second phase of the research. With the exception of logistics, all sectors were covered. The key aim of these conversations was to explore the developments throughout the recession, which had only just started when the fieldwork was originally undertaken in 2008. In particular, the questions aimed to understand the implications of the recession for older workers. After checking for any changes in the area of activity and workforce of the organisation, questions focussed on: the position of older workers, including demand and supply issues; the evaluation of their skills and experience; skills gaps; the employers' reaction to the (then) news that the state pension age was to be abolished; impact of the recession and spending cuts on the organisation as a whole and training and learning activities in particular. The interviews in both phases of the research lasted between 20 and 90 minutes. The majority of interviews were taped and transcribed for analysis. In the first research phase 7 respondents (of which 3 were 'employers') were 
uncomfortable with being taped, in the second phase only one respondent preferred notes to be taken instead of using a Dictaphone. The transcripts (or notes) were repeatedly re-read by the researcher to identify key words and phrases, a process that formed part of the qualitative content analysis. As Duriau et al. (2007) suggest, content analysis is a means to understand cognitive schemas that allow insights into values, intentions and attitudes, thus rendering visible a richness of meaning. Where quotes from the interviews are utilised in this paper, the year of the research (2008 for the first phase, 2010 for the second phase), sector and size of the company is provided to give context to the content of the quote. Due to the size of the sample and the geographic limitations (i.e. to a specific region with in the UK), the findings are indicative, though the depth of the conversations allows a deeper understanding of the specific learning contexts within organisations. Background questions and information conversations leading up to and following the interviews provided further insights into the the organisations' policies and practices.

The initial, key finding from this qualitative research was that there are few learning opportunities for older workers. There were, however, contextual differences (e.g. by sector and size of the organisation) as well as a number of informal arrangements that allow more detailed analysis of what learning takes place and how. As the majority of respondents stated that they did not provide any learning and training opportunities specifically for older workers, it seems that organisations are not responsive to demographic change. The abolition of the SPA was a new development at the time of the interviews but employers have known about the ageing of the workforce for some time. Due to the limited provision and consideration of learning issues by organisations, this paper takes a broad approach to the subject matter. Considerable research has been undertaken on workplace learning (for overviews see Fenwick, 2008b, Tynjälä, 2008) including various categorisations and distinctions but it is appropriate to talk about 'learning and training' here. Only where, for example, formal training or informal learning can be identified, will more specific language be utilised. This paper thus aims to explore employers' views on learning and training for older workers. 


\section{Older employees' views of learning and training}

It must first be considered that problems with learning may be due to either employer resistance or individual unwillingness (McNair, 2006) or indeed a combination of both. As the remainder of the paper considers employers, it is worth briefly looking at individual older workers' position. Employees have been found to see learning at work as independent of age (Paloniemi, 2006). Yet older workers' lower participation rates in training are at times due to a lack of self-confidence, negative self-perceptions (Porcellato et al., 2010), and previous negative experiences with education and training, especially in classroom-based settings. This has lead to perceptions that older workers do not want to learn or find it difficult to learn new explicit knowledge (compare Billett et al., 2011).

I've sat in on a number of meetings with people who are stony faced when they're in these training sessions, because they resent the prospect of having to spend a day out of the showroom not talking to customers and, you know, it seems that they resent the prospect of having to learn anything. But younger people are much more responsive, they know that they've not been in the industry very long. They know they've got a lot to learn and they know they can benefit from it. So it's almost, age and experience is starting to become a disadvantage to sales people. (2008, Retail, SME Employer)

In the retail sector, the issue of attitude and how it may become problematic as workers age was mentioned by respondents of different sized organisations. Following Eraut $(2004,261)$, such assumptions about older workers' motivation to learn are 'deceptive and fallacious' as they ignore the emotional dimension of the learning process, including the pain and loss of control over working practices when experience or tacit knowledge is no longer sufficient. Unfortunately, the interviews with employers in the retail sector did not shed any light on why some older workers were considered to have a bad or the 'wrong' attitude. Older workers are also reluctant to discuss their learning needs with their employers, as they fear exposure of their skill and qualification deficits (Mitton and Hull, 2006). Such vulnerability in 
the face of change influences the disposition towards remaining in the labour market, though it may be moderated by factors such as financial (in-)security or inherent enjoyment or discontent with a job or occupation (Herrbach et al., 2009, Vickerstaff et al., 2008). In increasingly knowledge based workplaces older workers may attempt to strengthen their position by not handing over and merely 'giving away' information (compare Tempest, 2003), causing potential skills gaps on retiring. Considering older workers' position highlights the need for learning and training opportunities that also address the concerns and fears of older participants, rather than merely providing necessary skills. Employers similarly view specific approaches and aims of workplace learning that differ according to the age of the workforce.

\section{Employers' views of learning and training for older workers}

For employers, learning and training provide important contributions to getting the necessary jobs done. From a human capital perspective (Becker, 1993), it is crucial to get the right people who have the right qualifications and skills or, alternatively, providing them with the right qualifications and skills in a 'learning as acquisition' tradition. As the following quote suggests, however, it is not necessarily easy to acquire the right people and skills.

[It is] difficult to get skills, difficult to get people, and when you the see the Chinese that are pushing on and developing and inventing, and then we've just, it's going to be reversed. We're going backwards in this country to be fair. (2008, Engineering, SME employer)

The engineering sector has struggled with the changing industrial climate and the lack of specific engineering education in Britain (Jones et al., 2000) and has become increasingly aware that it is not merely knowledge and skills but also attitudes that are important (Heinrich et al., 2007). In this scenario an engineer with the appropriate personal and human capital is a valuable asset. Yet it has been established that older workers are provided with less formal training and development (Felstead, 2011, Billet et al., 2011). The importance of former work experiences for engineers' work and learning has already been established (Collin, 2006) but employers may still not provide formal training if they are concerned that 
the worker will not work long enough to provide a return on investment (Hedge, 2008, Mayhew et al., 2008). In the UK, the abolishing of the SPA has substantially weakened the 'return on investment argument' as there is no set point at which a worker has to retire. The argument is especially weak in a high skilled profession such as engineering, which relies heavily on informal learning. The context should therefore encourage employers to invest into the human capital of their older workers.

Moving away from the human capital approach, informal workplace learning includes a broad set of activities that is not restricted to skill acquisition but may include personal transformation, collective empowerment, and other phenomena (Fenwick, 2008b). Informal learning activities are more difficult to identify and measure as they can occur incidentally whilst doing the job, working with colleagues or clients, reflecting on work, new challenges and activities outside of work (Tynjälä, 2008). At the same time, these activities may accord more opportunities for older workers across occupational, professional and hierarchical spectrums to become involved. This is not to deny that the distinctions between formal and informal learning are not only blurred (Sambrook, 2005) but inextricably inter-related (Malcolm et al., 2003) and dependant on the specific context in which the learning occurs. Experience held by older workers might exemplify this as it will usually be based on formal learning at the outset of an occupational career but will then have developed and formed within the specific context and opportunities throughout employment.

... new techniques are coming through all the time and the apprentices are taught the newest way at colleges, but there's nothing like a bit of experience, you know, how to problem solve and what's the best way to sort something out. I suppose it's like in any business really, the experience of having done the job for a long time, obviously gives you a lot of confidence and knowledge. (2008, Construction, SME employer)

It should be noted that this respondent is referring to crafts-based employees in the construction sector rather than un-skilled labourers. The quote implies contradictions in employers' views of older workers. Formal education and qualifications may have taught the 
'newest way' but in the case of older workers, this knowledge may be deemed out-dated. Older workers are therefore seen to have qualification and skill deficiencies that are often accompanied by insecurity and fear of exposure (Mitton and Hull, 2006). At the same time, employers rely on older workers' experience that gives them the ability to problem solve, do their job independently and well, and provides them with confidence and knowledge (Paloniemi, 2006). These strengths of older workers are acquired as part of informal learning activities which may include observation, posing questions, coaching, and working on projects, in teams or on secondments (Eraut, 2004, Sambrook, 2005). A dichotomy of stereotypes of older workers relating to skills and qualifications vs. experience thus emerged from employers' responses. An informal 'learning by doing' approach is here seen as a strength, in particular when contrasted with the expectations that employers considered young workers to have.

The next quote is a statement given by the Managing Director of a medium sized engineering company who was an older worker himself. The implicit message given by this interviewee was that because workplace learning in the organisation is informal, it is difficult for young, inexperienced workers to realise that learning is occurring whilst they are working (compare Tynjälä, 2008). Implicitly, the statement suggests that professionals such as engineers need to be aware and take (some) responsibility for their on-going learning and development.

One of these lads left us about 18 months ago and cited that he didn't get training. I fell of my chair. I said, look, part of it was that he didn't recognise what training he was getting because it wasn't formalised and it wasn't documented and he didn't have appraisals and he didn't have a chat one-on-one with his manager every three months and he didn't do this, and he didn't do that. So I think it's also, youngsters need to feel as though they're on a programme. (2008, Engineering, SME Employer)

The quote indirectly poses the question what training and, more broadly speaking, workplace learning is. In practice, informal learning in particular is less tangible and more difficult to keep tabs on. 
Although informal learning is clearly defined and considered to be important in the literature (Sawchuk, 2008, Tynjälä, 2008, Paloniemi, 2006), this is not always reflected in organisational contexts and in companies' rhetoric. Informal, experience-based learning processes are often well established in organisations even if, as in the following quote, they are not necessarily valued as equal to formal education and training.

Clearly there would be some peer support and more experienced maintenance people would work alongside less experienced, a kind of buddy system if you like. But that's invisible support. It's not something that we would bank on as a main method. (2008, Engineering, large MNC Employer)

Despite the somewhat negative evaluation of informal learning practices in the last quote, the majority of respondents to this research indicated that informal learning is important to their workplaces and to the knowledge exchange that occurs amongst their employees. This applies in particular to sectors where specialist skills are required but which do not have a strong educational structures to feed young workers into organisations. The fact that the majority of quotes in this section are from respondents in engineering shows that this occupation and sector is particularly reliant on informal learning.

They tend to look for role-models and latch on to them. (2008, Engineering, large MNC employer)

[T] he reality is that you spend quite a bit of your experience getting on with something that you've been given to do, you know, and then having some structured sessions with your mentor or the person that's kind of training you as you go along. (2008, Engineering, SSC)

Organisations thus benefit from the informal learning that occurs and can also influence and contribute to the occurrence of such learning. It was not specified who might act as a role model or mentor for older workers and whether they would be expected to take on this role for younger colleagues. The indication seems to be that older workers would provide such 
support. Organisations can facilitate access to learning, information, and opportunities to practice and develop new skills; support and reward learning (Ashton, 2004) and create, sustain and re-create a group climate for learning (Eraut, 2004). Yet the identified importance of informal learning within companies is accompanied by an undervaluing of such practices by some employers. This demonstrates the lack of coherence in preparing for or coping with demographic changes (LCCI and Penningtons, 2011) and managing an ageing workforce (see Parry and Tyson, 2011). Employers admit not having considered the broader implications of extending working lives (LCCI and Penningtons, 2011).

...that's definitely not something that we've actually looked at in any detail yet. If you think you might be working an extra five or ten years in an organisation, then you probably need to think very differently about your career path. (2010, Retail, large employer)

As suggested in this quote, this extends to career development, implying that respondents had not considered the longer-term implications of working with an ageing workforce (Bowen-Wilson, 2011). The lack of attention to the details of learning processes and the effects this may have on extending the working lives of older workers, raises the question how much and what kinds of learning and training opportunities older workers receive.

\section{Learning and training opportunities for older workers}

Felstead (2011) reports that older workers are not provided with a fair share of training, development and learning opportunities. This reinforces older workers generally having fewer qualifications than younger generations (Taylor, 2008). Across four life stages (up to 25; 2550; 50-75; over 75) current spending on lifelong learning in the UK is allocated in the proportion of 86: 11: 2.5: 0.5 (Schuller, 2010) signifying that 3 per cent of all spending on lifelong learning is for anybody above the age of 50. TAEN (2011b) also found the number of adult learners in government-funded further education to have fallen by 4.5 per cent in the academic year 09/10 when compared to the previous year. Qualitative statements from employers confirm these statistics. The following quote from the health sector is especially 
interesting because there is a considerable amount of mandatory training and consequently a comparatively high incidence of learning opportunities for professional staff in the sector. An admittance of 'starting from a low base' indicates an indictment of what would be considered a progressive employer of older workers.

So I think it's fair to say that the assumption is we're starting from a low base and at the moment, no, there isn't fair access. (2008, Health, large employer)

The quantity of learning and training opportunities apart, older workers receive training that tends to be shorter and of lower quality than that for younger people (Felstead, 2011). Whilst older workers are willing to pass on their experience to younger workers, they were "more likely than other age groups to problem-solve alone and to be left to their own devices" (ibid, 2011, 203). As a result, older workers' skills and knowledge tend to have been developed experientially, without accreditation and therefore remain under-recognised and under-valued (Mitton and Hull, 2006). The following quote clearly indicates that one particular older worker was dependent on 'sorting it out himself' if an opportunity to learn presented itself. The effects of not providing learning and career opportunities also need to be considered in that a poorly supported worker is here equated with a demotivated worker. Learning, or the lack thereof, has effects for both the organisation and the individual (Mann, 2011).

He'd been with the group for 20 years and it had changed hands and they'd stopped sending people on training and he was very despondent about that because a technician lives by his skills and if his skills aren't being honed with the introduction of new technology and new models that's happening in the trade all the time, then he's slipping back slowly but surely. The best that he can hope for is that he gets a new model with a new problem and he can try and sort it out himself, rather than have specialist training teaching new tricks of the trade. (2008, Retail, SME employer)

Unusually for the retail sector, the above statement concerns a professional technician rather than sales staff. Although there has been a general development to more practice-based, participative conceptions of learning, employers' considerations of older workers seem to 
reduce workplace learning to individual knowledge acquisition (compare Fenwick, 2008a). The present research results not only suggest that older workers receive less access to learning and training opportunities but also that employers expect and accept this to be the case. Respondents expected older workers to add knowledge or skills and even provide learning opportunities for their colleagues or co-workers rather than learning or being 'upskilled' themselves.

... when we bring somebody in of an older age, we want them to add something to the business. Somebody of a younger age, we're looking to support and train them. (2008, Engineering, large employer)

The approach to older workers as displayed in the last quote highlights the front-loaded nature of learning activities in education and workplaces (see Winch and Clarke, 2003). The drive to extend working lives has highlighted key problems with this frontloaded nature of learning and sets up an unhelpful dichotomy between older and younger workers. The former are expected to contribute to the business, apply and/or pass on their experience and knowledge whereas younger workers are expected to learn and benefit from more experienced colleagues who implicitly have roles such as mentor or role model added to their job. The age-diversity of workplaces could be utilised better. The ideal learning process would involve situations in which "the individual learner brings his or her personal knowledge, skills, attributes and previous experience, and learns and interacts dynamically with all others in the setting, including teachers, patients, peers and colleagues, and with other contextual influences" (Mann, 2011, 65). Mentoring relationships have been shown to lead to an increase in satisfaction amongst older workers (Stevens-Roseman, 2009). However, a further statement from the same engineering employer shows that there is not merely a dichotomy but a hierarchy of relationships.

You'll have a young lad who will come in, who will work for somebody who's been like a section leader or a project engineer who's been with the company for a number of 
years and then he in turn will work for the engineering manager who's been there longer. So it's sort of filtered down. (2008, Engineering, large employer)

The idea of structured roles and responsibilities in learning processes where knowledge is passed down the hierarchy begins to consider learning as a socially constructed process (Lave and Wenger, 1991). In the context of top-down knowledge transfers, it is not surprising that the relationship between older and younger workers has been conceptualised as one between experts and novices (Tempest, 2003). Situated learning theory's focus on the learning processes of new entrants, or novices (Lave and Wenger, 1991), disregards that older workers can also be considered as novices when they enter a new job, different sector or change their employment in other ways.

So I mean from my own experience, I came into this business with no practical experience of the particular trade, I mean I've been able to pick up quite a lot by just sort of being in that office environment and being able to learn from colleagues in the office. (2008, Engineering, SME employer, an older worker themself)

As part of social learning theories, the communities of practice approach has been criticised for not considering the further development of experts and for a poor conceptualisation of learning for 'full participants' (Fuller and Unwin, 2005). Although the interaction between novices and experts highlights the need for experienced and therefore potentially older workers, the hierarchical nature of learning has further disadvantages. Tempest (2003) highlights that traditional knowledge transfer does not make use of new ideas of novices thus leading to reduced development opportunities for organisations as a whole because the experiences, attitudes and abilities of all workers, including younger, potential novices, are not considered. Fuller and Unwin (2004) have shown that young apprentices are often involved in helping experienced and inexperienced colleagues to learn, thus demonstrating empirically that novices are not merely receivers in learning processes. Older workers acting as mentors or role models is a further issue that emerged from this research. Whilst the respondents might expect them to take on these responsibilities, not all older workers 
necessarily feel comfortable in such a role. Tynjälä (2008) highlights how conceptualising learning as participation for all would require a reorganisation of companies by focusing on working practices. The next section therefore considers how employers' value working practices that constitute older workers' experience.

\section{Utilising older workers' experience}

One of the last questions employers in both research phases were asked was how older workers' skills and experiences could be utilised better to establish ways in which employers could encourage older workers to remain in the labour market for longer. Learning opportunities are of particular importance because it is questionable whether older workers can continue to undertake their work without training or learning opportunities that ensure they are not lagging behind with required skills. The abolition of the SPA therefore necessitates far reaching changes in the way that learning opportunities are offered. Previous research has shown that older and younger workers alike mainly derive their competence from work experience, including learning to learn, awareness of one's strengths and formal and practical knowledge (Paloniemi, 2006). Respondents stated that they do not make use of older workers and their experiences as much as they could and possibly should. Even assessing the need for learning and training was reported to be problematic. Although larger organisations supposedly have more structured and therefore better learning and training opportunities (Bishop, 2008, Tynjälä, 2008), the following quote shows that this particular large employer struggled to assess the training needs and could therefore not address such needs.

\footnotetext{
And actually we're not very good at getting a training needs analysis. We end up with kind of wish lists and lists on spreadsheets, and they're not very evidence based. And if you did do it truly evidence based, that's when the experience comes in about the people that know, that are probably the people that have been there a while if you know what I mean. (2008, Health, large employer)
} 
Respondents mentioned two main reasons for not offering learning and training opportunities: cost and the lack of appropriate provisions. A number of respondents mentioned that whilst there was a host of courses and programmes, they were often disappointed with the results and the generic nature of the content of learning, thus confirming the existence of a gap between knowledge obtained via education and knowledge required to undertake a job (Tynjälä, 2008). It takes significant experience to be able to convert formal learning and theoretical knowledge into working practice (Paloniemi, 2006) though theoretical knowledge and practical competence have also been described as a continuum (Collin, 2006). As the following quote highlights, this should make employers more aware of the importance of working with in-house experiences and skills.

[T]here's just gulfs between what you can learn in an academic, developing new skills way and how that's actually implemented in real life working. (2008, Health, large employer)

A further key finding was that respondents' evaluations of the usefulness of learning and training differ strongly (Tynjälä, 2008), especially between sectors, occupations and skill levels. This was most obvious in the construction sector where older trades people might be given career opportunities to move into management or training but no such options existed for older labourers. The physical and unskilled nature of the work undertaken by these labourers means that employers do not see that they could be usefully kept on or trained for re-deployment. The organisation of work can thus be a pre-condition for learning (compare Tynjälä, 2008), especially when experience is not valued. Theoretically, a blend of knowledge, individuals and views in work teams benefits learning and innovation (Tempest, 2003) but this does not hold for all practices and business cases.

Well the types of people we're talking about are the general labourers. They're not qualified to do anything but what they do. [...] You can't have a man sweeping out the canteen all day. (2010, Construction, large employer) 
Low-skilled labourers apart, respondents did consider and, in part, utilised a number of ways in which older workers could be tied into the labour market via involvement in learning opportunities that would also benefit the employer. It must be made clear, however, that these strategies are highly context dependent. The most common way that employers utilise older workers skills and experiences is by promoting or developing them into management or working with apprentices. However, as these opportunities can not be offered to all older workers, arrangements were often only made for older workers who pro-actively sought such a change in their role. The respondents also emphasised that managing or working with young apprentices is not to everybody's liking. The interviews revealed further problems, for example in providing support and training to accompany the changes. There are clearly different skills required to work in the crafts or, as in the following quote, as a nurse and in a managerial position, even though the technical and practical experiences gained will continue to be useful.

\begin{abstract}
And there's also been this thing about when sort of very experienced nurses for example are promoted into positions of management, they're not necessarily trained to cope with those positions in terms of the managerial skills they need rather than the clinical skills they need. (2008, Health, large employer)
\end{abstract}

The limited, continued use of older workers that does happen would therefore benefit from a better integration of learning and training opportunities to ensure that older workers are well prepared for their new roles and can contribute to the organisation. A further possibility to emerge out of the provision of such opportunities would be in formal assessor, mentor or training roles. Whilst the mentor or training role is often done informally, becoming an assessor would require the undertaking of a formal qualification.

[O]lder workers could undertake assessor training, so that they can assess building on their experience, become a qualified assessor or workplace mentor to support the younger workers. So the experience isn't lost, but they might not necessary be doing 
the managerial aspect, but they're still keeping their skills within the company. (2008, Construction, SSC)

In addition to the benefit for the organisation, in particular in retaining skills and experiences, there are indications that such involvement in learning activities has much broader benefits and can include an increase in work satisfaction (Stevens-Roseman, 2009, Fuller and Unwin 2004). One engineering company had introduced a variation of such an attempt to utilise older workers and was bringing back a very experienced worker from retirement because they were unable to fill the skills gap the individual had left. However, the worker was unwilling to come back even on a part time basis and merely 'helped out' on an informal basis to get specific jobs done. It was therefore not clear whether there was an intention to institute a learning process for the retiree to pass on their knowledge and experience. As organisations generally seem to struggle with tapping into the resources that older workers constitute some Sector Skills Councils and trade unions had taken the initiative.

The following example from the retail sector, which does not have high skills requirements, therefore builds on the experience and skills that workers may have and focuses on building esteem, self-confidence and self-worth (compare Jewson and Huam, 1995). However, this qualification was still being developed and was exceptional in its attempt to provide specific training and acknowledgement of experience on the part of older workers.

I'm currently looking at doing some work with our union [...] about some sort of viable alternative to a level 2 qualification for the older worker, which really would introduce a lot more personal learning and thinking skills, a lot more confidence and self-esteem building. (2008, Retail, SSC)

The implication of 'personal learning' and 'thinking skills' is that a reflexive process is required to ensure application and implementation of knowledge to the real world. Such an approach to learning would respond to older workers' concerns as outlined at the outset of this paper. In addition, it could address skills gaps and utilise inter-generational diversity in teams to mutual advantage (see Armstrong-Stassen and Lee, 2009). Individuals, groups or 
organisations would be released from a reliance on static levels of expertise as a foundation for effective learning, allowing openness to new possibilities and opportunities of learning (see Tempest, 2003). There is potential for a more equal treatment of workers as their different skills, experiences and knowledge are valued, thus leading to enhanced motivation in the workforce as all workers are engaged in helping others.

\section{Conclusion}

The UK workforce is ageing. The policy response has been to abolish the state pension age and encourage or enforce the extension of working lives. This is a top-down initiative to address fiscal (pension payments) problems, which may also ensure that there are sufficient numbers in the workforce. The broader implications, including social issues and individual concerns as well as learning and training requirements have not been addressed. This is reflected in employers' behaviour and attitudes towards older workers, which do not seem to have changed with the demographic developments. Older workers continue to receive less education and training, especially in formal settings. Informal learning occurs and in sectors such as engineering is an important part of working, though respondents did not necessarily value this type of engagement. Respondents were clearly aware of this informal learning because in engineering it was expected that older workers provide learning opportunities for others. This means that organisations need to consider the role of older workers both with regards to their own learning and in the context of providing learning opportunities for others. In most organisations the two are entwined meaning that it can be hidden how few learning opportunities for older workers might exist.

The results from this study show that the opportunities for engagement between workers of different ages and stages of the occupational hierarchy to work and learn together in a conducive environment varied. The formal qualification requirements in construction and to some extent in health meant that older workers were considered as assessors or facilitators, whereas in the shallow hierarchies of the retail sector, discussions centred on facilitation for example via reflexive learning practices. The possibilities for older workers to be more 
involved are thus dependent on the established learning practices and cultures (e.g. formal informal), the type of knowledge required, organisational structures and individual factors. Not all older workers are keen to work with younger peers and take on additional responsibilities. Organisations similarly have views on which older workers they would be happy to see influencing young colleagues. However, it must be questioned whether such practices have to be formalised as young workers are already described as preferring structured training and not recognising informal learning. These necessary considerations meant that few respondents had specifically addressed what role older workers might play in organisational learning processes. Where such learning occurred it was therefore likely to be incidental rather than supported and intended. The everyday practice of workplace learning therefore still seems to adhere to a 'front-loaded' model of learning and training, which is focussed on younger workers. Ensuring that organisations or HR departments more specifically are aware of the potential problems and opportunities of older workers (lack of) engagement with learning opportunities are important first steps to changing practices.

A further important factor determining what role older workers might play in organisational learning processes is the value (or otherwise) attached to the knowledge and experience they have accumulated. There are considerable sectoral differences in the assessment whether older workers are considered to be experienced. Experience is rarely expected and valued for the comparatively low skilled work undertaken by older workers in retail, logistics and parts of the construction industry (e.g. labourers). In retail in particular, respondents considered age to be a disadvantage because it was seen as incompatible with the 'right' attitude for the job. In the professional occupations including most of engineering and health, and the crafts in the construction sector the length of service tends to be related to the level of expertise. In engineering, recruitment from a pool of early career or less experienced individuals was not seen to be viable as such candidates did not fulfil the skill requirements. It is thus those sectors and occupations where older workers are considered to be experienced and therefore valued where they are more likely to be involved in learning processes that incorporate them passing on their expertise. At its most extreme, in the engineering sector, this situation also 
entails skills shortages because there is no readily available pool of skilled and experienced workers, other than those in the older workers' category. In this situation it is necessary to change recruitment expectations and hire (older) workers who are still in need of training and support.

Given the broader societal context of ageing societies, it must be questioned how organisations intend to incorporate learning and business strategies (Tynjälä, 2008). Where organisations find it difficult to recruit or retain younger workers (as is already occurring in some sectors such as engineering) the responsibility and motivation to learn becomes more urgent. Employers will have to take a more pro-active stance on questions including who gets access to learning and training and how informal learning is evaluated and acknowledged. The responses to this research showed that employers not only juxtapose older workers vs. younger workers but also skills and qualifications vs. experience and tacit knowledge. These juxtapositions are unhelpful (see Paloniemi, 2006). Positive examples of working with older workers and utilising their experience demonstrate that a more even treatment of individual skills, knowledge and experience would result in a higher performing workforce. Support and encouragement for informal learning and acknowledgement of its results would play an important part. Yet informal learning alone is also insufficient (Tynjälä, 2008) as the social and cultural context of learning are intertwined with individual work experience (Collin, 2006). Can we expect employers to get it right in a society and culture in which we are still woefully underprepared for changes in demography and in the way that working life will be organised? 


\section{References}

Argote, L. (2011) 'Organizational learning research: Past, present and future', Management Learning 42(4): 379-393.

Armstrong-Stassen, M. and Lee, S.H. (2009) 'The effect of relational age on older Canadian employees' perceptions of human resource practices and sense of worth to the organization', The International Journal of Human Resource Management 20(8): 1753-1769.

Ashton, D. (2004) 'The impact of organisational structure and practices on learning in the workplace', International Journal of Training and Development 8(1): 43-53.

Beck, V. (2010) 'Older workers, older learners: the contribution of employers in the British East Midlands', in Cedefop (ed) Working and ageing: Emerging theories and empirical perspectives, pp. 280-294. Luxembourg: Publications Office of the European Union.

Becker, G. (1993) Human Capital, A theoretical and empirical analysis with special reference to education. Chicago: The University of Chicago Press.

Billet, S., Dymock, D., Johnson, G. and Martin, G. (2011) 'Overcoming the paradox of employers' views about older workers', The International Journal of Human Resource Management 22(6): 1248-1261.

Billett, S. (2002) 'Critiquing Workplace Learning Discourses: Participation and Continuity at Work', Studies in the Education of Adults 34(1), 56-67.

Billett, S. (1999) 'Guided Learning at Work' in D. Boud and J. Garrick (eds) Understanding Learning at Work, pp. 151-164. London: Routledge.

Bishop, D. (2008) 'The Small Enterprise in the Training Market', Education + Training 50(8/9): 661-673. 
Bowen-Wilson, D. (2011) 'The Role of Age in Career Progression: Motivation and Barriers to Fulfilment in Older Employees' in E. Parry and S. Tyson (eds) Managing an Age Divers Workforce, pp. 129-149. Basingstoke: Palgrave.

Bryman, A. (2004) Social Research Methods, Oxford: Oxford University Press.

Collin, K. (2006) 'Connecting work and learning: design engineers' learning at work', Journal of Workplace Learning 18(7/8): 403-413.

Dini, E. (2009) 'Older workers in the UK: variations in economic activity status by sociodemographic characteristics, household and caring commitments', ONS Population Trends $137,11-24$.

Duriau, V., Reger, R. and Pfarrer, M. (2007) A Content Analysis of the Content Analysis Literature in Organization Studies, Organizational Research Methods, 10(1): 5-34.

EC (2009) 2009 Ageing Report: Economic and budgetary projections for the EU-27 Member States (2008-2060). European Commission DG Economic and Financial Affairs, Brussels.

Eraut, M. (2004) 'Informal learning in the workplace', Studies in Continuing Education 26(2): 247-273.

Felstead, A. (2011) 'The Importance of 'Teaching Old Dogs New Tricks': Training and Learning Opportunities for Older Workers' in E. Parry and S. Tyson (eds) Managing an Age Divers Workforce, pp. 189-205. Basingstoke: Palgrave.

Fenwick, T. (2008a) 'Understanding Relations of Individual-Collective Learning in Work: A Review of Research', Management Learning 39(3): 227-243.

Fenwick, T. (2008b) 'Workplace Learning: Emerging Trends and New Perspectives', New Directions for Adult and Continuing Education 2008(119): 17-26.

Fuller, A. and Unwin, L. (2005) 'Older and wiser?: workplace learning from the perspective of experienced employees', International Journal of Lifelong Education 24(1): 21-39. 
Fuller, A. and Unwin, L. (2004) 'Young people as teachers and learners in the workplace: challenging the novice-expert dichotomy', International Journal of Training and Development 8(1): $32-42$.

Geiger, D. and Schreyögg, G. (2009) 'Coping with the Concept of Knowledge: Toward a Discursive Understanding of Knowledge', Management Learning 40(4): 475-480.

Hedge, J. (2008) 'Strategic Human Resource Management and the Older Worker', Journal of Workplace Behavioural Health 23(1/2): 109-123.

Heinrich, E., Bhattacharya, M. and Rayudu, R. (2007) Preparation for lifelong learning using ePortfolios, European Journal of Engineering Education 32(6): 653-663.

Herrbach, O., Mignonac, K., Vandenberghe, C. and Negrini, A. (2009) 'Perceived HRM Practices, Organizational commitment, and voluntary early retirement among late-career managers', Human Resource Management 48(6): 895-915.

Heywood, J., Jirjahn, U. and Tsertsvardze, G. (2010) Hiring older workers and employing older workers: German evidence, Journal of Population Economics, 23: 595-615.

Jewson, N. and Huam, C.K. (1995) 'Changing hearts and minds: training programmes for 'mid-career' workers in Singapore', Working Papers, Centre for Labour Market Studies, University of Leicester, No 7.

Jones, B., Scott, P., Bolton, B., Bramley, A. and Manske, F. (2000) The British Engineer Problem: A Comparison of Careers, Employment and Skills, Policy Studies 21(1): 5-23.

LCCI and Penningtons (2011) Tackling the age-old problem of retirement. London: London Chamber of Commerce and Industry and Penningtons Solicitors.

Lave, J. and Wenger, E. (1991) Situated Learning. Cambridge: Cambridge University Press.

Malcolm, J., Hodkinson, P. and Colley, H. (2003) 'The interrelationships between informal and formal learning', Journal of Workplace Learning 15(7/8): 313-318. 
Mann, K. (2011) 'Theoretical perspectives in medical education: Past experience and future possibilities', Medical Education 45(1): 60-68.

Maurer, T. (2001) 'Career-relevant learning and development, worker age, and beliefs about self-efficacy for development', Journal of Management 27(2), 123-140.

Mayhew, K., Elliott, M. and Rijkers, B. (2008) 'Upskilling older workers', Ageing Horizons 8: $13-21$.

McNair, S. (2011a) Older people and skills in a changing economy, London: UK Commission for Employment and Skills.

McNair, S. (2011b) Learning, work and later life in the UK: guidance needs of an ageing workforce, in: Cedefop (ed.) Working and ageing, Guidance and counselling for mature learners, Luxembourg: Publications Office for the European Union, 126-144.

McNair, S. (2006) 'How different is the older labour market? Attitudes to work and retirement among older people in Britain', Social Policy and Society 5(4), 485-495.

McNair, S., Flynn, M. and Dutton, N. (2007) Employer responses to an ageing workforce: a qualitative study. London: AgePartnershipGroup / DWP.

Mitton, L. and Hull, C. (2006) The Information, Advice and Guidance Needs of Older Workers, Social Policy and Society 5(4): 541-550.

ONS (2009) 'Labour market: more older people in employment between 1996 and 2008' available at: http://www.statistics.gov.uk/cci/nugget.asp?id=1266 (accessed 4 February 2011).

Ozawa, M. and Lum, T. (2005) 'Men who work at age 70 or older', Journal of Gerontological Social Work 45(4): 41-63.

Paloniemi, S. (2006) 'Experience, competence and workplace learning', Journal of Workplace Learning 18(7/8): 439-450. 
Parry, E. and Tyson, S. (eds) (2011) Managing an Age Divers Workforce. Basingstoke: Palgrave.

Parry, E. and Tyson, S. (2009) 'Organizational reactions to UK age discrimination legislation', Employee Relations 31(5): 471-488.

Phillipson, C. (2010) 'Active Ageing and universities: engaging older learners', International Journal of Education and Ageing 1(1): 9-22.

Porcellato, L., Carmichael, F., Hulme, C., Ingham, B. and Prashar, A. (2010) 'Giving older workers a voice: constraints on the employment of older people in the North West of England', Work, Employment and Society 24(1): 85-103.

Sambrook, S. (2005) 'Factors influencing the context and process of work-related learning: synthesizing findings from two research projects', Human Resource Development International 8(1): 101-119.

Sawchuk, P. (2008) 'Theories and methods for research on informal learning and work: towards cross-fertilization', Studies in Continuing Education 30(1): 1-16.

Schuller, T. (2010) 'Learning Through Life: the implications for learning in later life of the NIACE Inquiry', International Journal of Education and Ageing 1(1), 41-52.

Stevens-Roseman, E. (2009) 'Older Mentors for Newer Workers: Impact of a Worker-Driven Intervention on Later Life Satisfaction', Journal of Workplace Behavioural Health 24(4): 419426.

TAEN (2011a) Newsletter New Year 2011. London: The Age and Employment Network.

TAEN (2011b) Number of Adult Learners Falls. London: The Age and Employment Network.

Taylor, P. (2008) 'Sing if you're glad to be grey. Working towards a happier older age in the United Kingdom' in P. Taylor (ed.) Ageing Labour Forces, Promises and Prospects, pp. 84110. Cheltenham: Edward Elgar. 
Tempest, S. (2003) 'Intergenerational Learning. A Reciprocal Knowledge Development Process that Challenges the Language of Learning', Management Learning 34(2): 181-200.

Tynjälä, P. (2008) 'Perspectives into learning at the workplace', Educational Research Review 3: $130-154$.

Urwin, P. 2006, 'Age discrimination: legislation and human capital accumulation', Employee Relations 28(1): 87-97.

Vickerstaff, S. (2010) 'Older Workers: The 'Unavoidable Obligation' of Extending Our Working Lives', Sociology Compass 4(10): 869-879.

Vickerstaff, S., Loretto, W., Billings, J., Brown, P., Mitton, L., Parkin, T. and White, P. (2008) Encouraging labour market activity among 60-64 year olds. Norwich: Research Report No 531, Department for Work and Pensions.

Winch, C. and Clarke, L. (2003) 'Front-loaded' Vocational Education versus Lifelong Learning. A Critique of Current UK Government Policy', Oxford Review of Education 29(2): 239-252. 
June 2012

I would again like to thank you for the detailed and constructive feedback that you have provided. This has now been addressed and the following points outline what work has been undertaken.

- p. 1: The abstract has been rewritten and now briefly summarises the aim of the research, what empirical research was conducted and the main findings.

- p. 1: an explanation of 'TAEN' has been included

- p. 3: The sub-heading on p. 3 has been changed from 'Different approaches to training and learning' to 'Methods and the research process'

- p. 4: An explanation of the strengths and weaknesses of the approach taken has been added at the end of the first paragraph. In addition, the drawbacks of the data are outlined in terms of the conflation of sectors, type of job and level of worker as well as the different categories of respondents (p. 4). Apart from addressing this point here, a clearer indication has been given throughout the paper what aspect of work, what kind of work or level of worker any quotes refer to. This is also discussed in the revised conclusion. Due to the nature of the data collected, it has not been possible to 'solve' this problem, but in line with Reviewer One's third point, it has been clarified.

- p. 5: The analytical approach has been specified (content analysis) and strengths of this approach for this particular research indicated.

- p. 7: A new sub-heading has been added on p. 7 (Older employees' views of learning and training)

- p. 20f: The conclusion has been rewritten. The main themes are now the overall lack of learning opportunities for older workers; the assumption that older workers are experienced; the most affective role for older workers in peer learning, how this differs by sector and what reasons employers have for promoting (or otherwise) these roles. This responds to the three themes indicated by Reviewer One. The conclusions also provide an indication of implications for practitioners as mentioned by Reviewer Two.

- The paper has been proof read and checked for punctuation and spelling mistakes. 